Ortodonti kliniğine başvuran ebeveynlerin pediatrik uyku apnesi hakkındaki görüşleri ve bilgi düzeyleri

\section{Knowledge and attitudes about pediatric sleep apnea among parents in an orthodontic clinic}

\author{
Yrd. Doç. Dr. Banu Sağlam Aydınatay \\ Hacettepe Üniversitesi, Diş Hekimliği Fakültesi, \\ Ortodonti A.D., Ankara
}

\section{Prof. Dr. Müge Aksu}

Hacettepe Üniversitesi, Diş Hekimliği Fakültesi, Ortodonti A.D., Ankara

Prof. Dr. Tülin Taner

Hacettepe Üniversitesi, Diş Hekimliği Fakültesi, Ortodonti A.D., Ankara

Geliş tarihi: 03 Nisan 2017

Kabul tarihi: 29 Haziran 2017

doi: 10.5505/yeditepe.2017.25744

\section{Yazışma adresi:}

Yrd. Doç. Dr. Banu Sağlam Aydınatay Hacettepe Üniversitesi, Diş Hekimliği Fakültesi, Ortodonti AD, Sıhhiye, Ankara 06100, Türkiye Tel: 03123052290

E-posta: banusaglam@hotmail.com
ÖZET

Amaç: Bu kesitsel çalışmanın amacı ebeveynlerin pediatrik uyku apnesi ile ilgili bilgilerini ve ortodontistin bu hastalığın teşhis ve tedavisindeki yeri ile ilgili fikirlerini değerlendirmektir.

Gereç ve Yöntem: Pediatrik uyku apnesi hakkındaki farkındalık ve görüşleri ölçmek üzere tasarlanmış bir anket, çocuklarının ortodontik tedavisi için bir üniversite ortodonti kliniğine başvuran uygun örneklem grubu ebeveynlere uygulandı. Elde edilen veriler ortalama ve sıklıkları içeren tanımlayıcı istatistikler ile analiz edildi. Demografik değişkenler ile sorgulanan bilgi maddeleri arasındaki korelasyonlar Pearson ki-kare testi kullanılarak incelendi.

Bulgular: Anket toplam 260 ebeveyn tarafından cevaplandı.

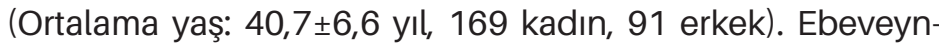
lerin çoğu, diş hekimleri ve ortodontistlerin tıbbi hastalık riskleri yönünden çocuklarında değerlendirme yapmasının çok önemli olduğu görüşündeydi (sırasıyla $\% 76,5$ ve $\% 76,2$ ). Ebeveynler aynı zamanda ortodontistin çocuklarını uyku apnesi riski yönünden değerlendirmesini isteyeceklerini $(\% 92,7)$ ve eğer ortodontist yönlendirirse uyku apnesi açısından değerlendirilmek üzere çocuklarını doktora götüreceklerini $(\% 97,5)$ belirttiler. Çoğu ebeveyn pediatrik uyku apnesi hakkında temel düzeyde bir bilgiye sahip olmasına rağmen, bu hastalığın etyolojisi, semptomları, teşhisi, sonuçları ve tedavileri hakkında bilgileri yoktu. Artmış eğitim seviyesi, pediatrik uyku apnesi hakkındaki bilgi düzeyi ile anlamlı düzeyde ilişkiliydi $(p<0,05)$.

Sonuç: Sonuçlar ortodonti kliniğine başvuran ebeveynlerin çocuklarının uyku apnesi yönünden incelenmesine olumlu baktığını göstermiştir. Ancak bilgi düzeylerinin düşüklüğü, ebeveynler arasında pediatrik uyku apnesi farkındalığını arttırmak için eğitsel yöntemlerin geliştirilmesi gerekliliğini ortaya koymuştur.

Anahtar kelimeler: Obstrüktif uyku apnesi, bilgi düzeyi, anket

\section{SUMMARY}

Aim: The purpose of this cross-sectional study was to assess parents' knowledge on pediatric sleep apnea and their attitudes regarding the role of the orthodontist in the diagnosis and management of sleep apnea.

Materials and Methods: A questionnaire designed to evaluate awareness and views about pediatric sleep apnea was given to a convenience sample of parents visiting a university clinic for the orthodontic treatment of their children. Data were analyzed using descriptive statistics including means and frequencies. Pearson's chi-square statistics were used in order to determine the correlation between knowledge items questioned and demographic variables.

Results: The survey was completed by 260 parents (mean age: $40.7 \pm 6.6$ years, 169 female, 91 male). The majority of parents thought it was very important for dentists and ortho- 
dontists to identify increased risk for medical conditions (76.5\% and $76.2 \%$, respectively). The parents were also willing to have an orthodontist screen their child (92.7\%) and they would accept a referral to a sleep specialist if suggested by the orthodontist (97.5\%). Even though most of the parents had some basic knowledge about the disease, the majority did not know about the etiology, signs and symptoms, diagnosis, health consequences and treatment of pediatric sleep apnea. A higher educational level and knowledge about the disease showed a statistically significant relationship $(p<0.05)$.

Conclusion: The results showed that the parents are well-disposed towards chairside screening for sleep apnea in an orthodontic clinic. Low knowledge level showed the need of developing educational interventions aimed at optimizing pediatric sleep apnea knowledge among parents.

Keywords: Obstructive sleep apnea, knowledge level, questionnaire

\section{Giriș}

Uyku Apnesi Sendromu tüm çocukluk yaş gruplarında görülebilen, uykuda artmış faringeal kollapsa ve üst havayolu rezistansına bağlı gelişen horlama ve/veya artmış solunum eforu ile karakterize bir hastalıktır. ${ }^{1}$ Çocuklarda uyku apnesi görülme sıklığı \%1-4 arasında rapor edilmektedir. ${ }^{2,3}$ Çocukluk döneminde görülen uyku apnesinin en yaygın etyolojik faktörü büyümüş adenoid ve/veya tonsiller ile obezitedir. ${ }^{4}$ Maksiller ve mandibuler retrognati, artmış yüz yüksekliği, azalmış yüz genişliği ve artmış overjet gibi kraniyofasiyal anomaliler de havayolu morfolojisindeki değişiklikler ve solunum problemleri ile ilişkilidir. ${ }^{5-7}$ Çocuklarda uyku apnesinin tedavi yöntemleri etyolojik faktöre göre değişiklik gösterir. Tonsillektomi ve/veya adenoidektomi ve CPAP en sık kullanılan tedavi yöntemleridir. Ayrıca kraniyofasiyal anomalileri olan çocuklarda fonksiyonel ortopedik apareyler ve cerrahi-ortodontik yaklaşımlarla başarılı tedavi sonuçları elde edilebilmektedir. ${ }^{8}$

Tedavi edilmeyen uyku apnesi sendromu nörobilişsel gelişimde geriliğe, okul performansında azalmaya, davranışsal sorunlara, kardiyovasküler morbiditeye, metabolik problemlere ve noktürnal enüreze yol açabilir. ${ }^{9}$ Ancak tüm bu olumsuz sonuçlarına rağmen, uyku apnesinin pediatrik populasyondaki teşhis oranları hala yetersizdir. ${ }^{10}$ Çocuklarda görülen uyku apnesi konusunda farkındalığın arttıııması ve taramanın yaygınlaştırııması daha erken tedaviye ve morbiditenin azaltılmasına katkıda bulunacaktır. Bu nedenle çocukların uyku apnesi yönünden değerlendirilmeleri tüm hekim gruplarının rutin klinik uygulamaları arasında yer almalıdır.

Son yıllarda yapılan yayınlarda diş hekimlerinin uyku apnesinin tedavisindeki rollerine ek olarak hastalığın ilk teşhisi ve uykuyla ilişkili solunum bozukluklarıyla ilgilenen medikal bölümlere yönlendirmelerin yapılması konusundaki sorumlulukları üzerinde de durulmaktadır. ${ }^{11,12}$ Ancak Bian $^{13}$ yaptığı çalışmada uyku apnesi konusunda doktorlar ve diş hekimleri arasındaki kooperasyonun "zayıf" olduğunu, dişhekimlerinin yarısından fazlasının klinikte uyku apnesinden şüphelendikleri bir hastaları olduğunda doktordan konsültasyon istemediklerini rapor etmiştir. Ülkemizde ortodonti kliniklerine tedavi için başvuran çocuk sayısının çok fazla olması nedeniyle ortodontistler uyku apnesine yönelik taramanın yapılmasında etkin bir rol üstlenebilir ve gerekli gördükleri durumlarda daha ileri değerlendirmeler için gerekli yönlendirmeleri yapabilirler. Ancak eğer hastalar yönlendirme yapılmasına rağmen kooperasyon göstermez ve doktora başvurmazlarsa teşhis oranlarının arttırılması mümkün olmayacaktır. ${ }^{14}$

Bireylerin sağlık davranışlarını açıklamak için geliştirilen Sağlık İnanç Modeli'ne göre tıbbi önerilere gösterilen kooperasyonu belirleyen faktörlerden birisi de hastalık hakkındaki bilgi düzeyidir. ${ }^{15} \mathrm{Bu}$ nedenle çalışmamızda çocuklarının tedavisi için ortodonti kliniğine başvuran ebeveynlerin pediatrik uyku apnesi ile ilgili bilgilerini ve ortodontistin bu hastalığın teşhis ve tedavisindeki yeri ile ilgili fikirlerini değerlendirmeyi amaçladık.

\section{GEREÇ VE YÖNTEM}

Çalışmanın etik kurul onayı Hacettepe Üniversitesi Girişimsel Olmayan Klinik Araştırmalar Etik Kurulu'ndan alındı (Onay No: GO 16/375-20) ve çalışma Helsinki Deklerasyonu Prensipler'ine uygun olarak yürütüldü. Çalışma grubu üniversitemizin Ortodonti Anabilim Dalı'na çocuklarının tedavisi için başvuran ebeveynler arasından oluşturuldu. Kapsamlı bir literatür taramasının ardından bu çalışmanın amacına uygun olarak kullanılabilecek hazır veri toplama aracı mevcut olmadığı görüldüğü için uyku tıbbında uzman olan 5 hekim, 3 ortodontist ve anket sorularının oluşturulması konusunda deneyimli 1 epidemiyolog tarafından yeni bir anket tasarlandı. Hazırlanan anket anlaşılabilirlik ve tamamlama kolaylığının belirlenebilmesi için 15 ortodontist ve 25 ebeveyn tarafından dolduruldu. Bu kişilerle yüzyüze yapılan görüşmeler çerçevesinde gerekli düzeltmeler yapılarak anketin son hali oluşturuldu. Anketin son halinde kullanılan sorular Tablo 1'de görülmektedir.

Ankette demografik sorular, görüş soruları ve pediatrik uyku apnesinin tanımı, etyolojisi, bulgu ve semptomları, teşhisi, etkileri ve tedavisi konusunda bireyin bilgisini ölçen; Doğru, Yanlış ve Bilmiyorum olarak cevaplanan 18 bilgi sorusu mevcuttu.

Anket, bilgilendirilmiş olurlarının alınmasının ardından çocuklarının ortodontik tedavisi için kliniğimize başvuran ve ortalama yaşları 40,7 yıl olan uygun örneklem grubu 260 ebeveyne uygulandı. 
Okuma yazma bilmeyen, kendisi veya eşi sağlık personeli olan, çocuğuna daha önce uyku apnesi teşhisi konmuş veya araştırmaya katılmak istemeyen ebeveynler çalışmaya dahil edilmedi.

İstatistiksel değerlendirme için SPSS, Version 21.0 (IBM SPSS Statistics for Windows, Version 21.0. Armonk, NY: IBM Corp.) kullanıldı. Elde edilen veriler tanımlayıcı istatistikler ile analiz edildi. Hastaların bilgi sorularına verdikleri cevapların çoğu "Bilmiyorum" olduğu için Faktör Analizi kullanılamadı ve demografik değişkenler ile sorgulanan tüm bilgi maddeleri arasındaki korelasyonlar Pearson kikare testi kullanılarak incelendi. $p<0,05$ istatistiksel anlamlı olarak değerlendirildi.

Tablo 1. Bilgi sorularına verilen cevaplar

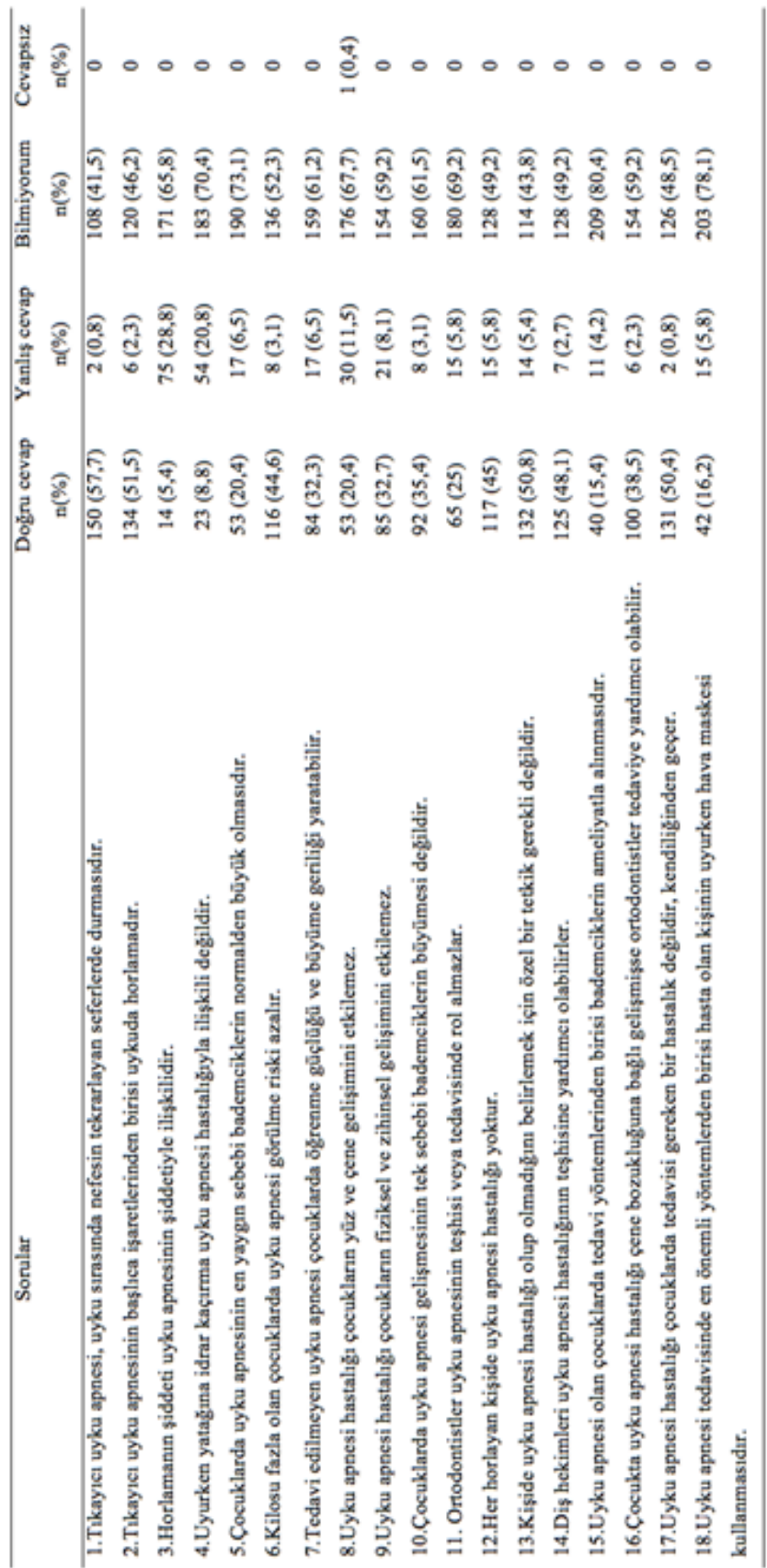

\section{BULGULAR}

Çalışma grubuna ait demografik veriler Tablo 2'de gösterilmiştir. Anket 169'u kadın, 91'i erkek toplam 260 ebeveyn tarafından cevaplandı. Ebeveynlerin ortalama

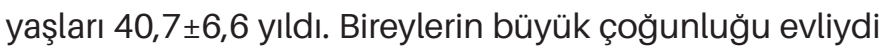
$(\% 95,8)$. Yaklaşık \%31'i lise mezunuyken, \%36'sı ise yükseköğretim ve üstü öğrenim düzeyine sahipti. Sadece \%44'ü halen gelir getiren bir işte çalışmaktaydı ve \%71'i ekonomik durumlarını orta olarak tanımlıyordu. \%64'ü 12 yaşına kadar bir il merkezinde yaşamışken, şu anda il merkezinde yaşayanların oranı \%93'tü.

Bireylerin çoğunluğu sağlık hizmetlerine kolay ulaşabildiklerini belirtmişlerdi (\%94). Kendisi veya eși dışında aile bireyleri arasında veya yakın çevresinde sağlık personeli olanların oranı \%36'ydı ve bireylerin sadece \%14'ü sağlık konularında bir eğitime katılmışlardı. Ebeveynlerin \%77'si diş hekimlerinin, \%76'sı ise ortodontistlerin tıbbi hastalık riskleri yönünden çocuklarında değerlendirme yapmasının çok önemli olduğu görüşündeydi. Ebeveynlerin \%94'ü ortodontistin çocuklarını uyku apnesi riski yönünden değerlendirmesini isteyeceklerini ve \%99'u eğer ortodontist yönlendirirse uyku apnesi açısından değerlendirilmek üzere çocuklarını doktora götüreceklerini belirttiler. Bireylerin sadece \%40'ı uyku apnesi hastalığının ne olduğunu bildiklerini söylerken, çoğu bu hastalığa ait bilgiyi birden fazla kaynaktan edindiklerini belirttiler. Bilgi kaynakları sırasıyla aile ve/veya arkadaş çevreleri (\%49), internet siteleri (\%42), televizyon (\%34), doktor (\%27) ve gazete/dergi (\%15) olarak bildirildi. Sadece 3 hasta bu bilgiyi diş hekiminden aldıklarını belirttiler.

Tablo 2. Hastaların demografik özellikleri ve bu özelliklerin sorgulanan bilg

\begin{tabular}{|c|c|c|}
\hline Değişken & $\begin{array}{l}\text { Bireyler } \\
(n=260)\end{array}$ & $p$ değer aralığ $1^{*}$ \\
\hline & Ortalama \pm SS (Min-Maks) & \\
\hline \multirow[t]{2}{*}{ Yaş-yıl } & $40.7 \pm 6.6(27-62)$ & $0,06-0,97$ \\
\hline & Sayı (\%) & \\
\hline \multicolumn{2}{|l|}{ Cinsiyet } & \multirow[t]{3}{*}{$0,27-0,82$} \\
\hline Kadın & $169(65)$ & \\
\hline Erkek & 91(35) & \\
\hline Gelir getiren işte çalışıyor & $114(44)$ & $0,14-0,80$ \\
\hline \multicolumn{3}{|l|}{12 yaşına kadar yaşadığı yer } \\
\hline İl & $167(64)$ & \multirow{4}{*}{$0,12-0,77$} \\
\hline İlçe-köy & $77(30)$ & \\
\hline Yurtdışı & $2(1)$ & \\
\hline Cevapsiz & $14(5)$ & \\
\hline \multicolumn{3}{|l|}{ Şu anda yaşadığı yer } \\
\hline ill & $242(93)$ & \multirow{4}{*}{$0,20-0,96$} \\
\hline İlçe-köy & $13(5)$ & \\
\hline Yurtd1ş1 & $0(0)$ & \\
\hline Cevapsız & $5(2)$ & \\
\hline \multicolumn{3}{|l|}{ Ekonomik durum } \\
\hline $\begin{array}{l}\text { İyi } \\
\end{array}$ & $53(20)$ & \multirow{3}{*}{$0,12-0,69$} \\
\hline Orta & $186(72)$ & \\
\hline Kötü & $21(8)$ & \\
\hline Ailede sağlık personeli olan & $94(36)$ & $0,23-0,85$ \\
\hline Sağlıkla ilgili eğitime katılmış & $37(14)$ & $0,14-0,97$ \\
\hline \multicolumn{2}{|l|}{ Eğitim düzeyi } & \multirow{4}{*}{$0,01-0,04 * *$} \\
\hline Yükseköğretim ve üstü & $93(36)$ & \\
\hline Lise & $81(31)$ & \\
\hline Ortaokul ve altı & $86(33)$ & \\
\hline
\end{tabular}

SS, standart sapma; Min, minimum; Maks, maksimum

* Demografik değişkenler ile sorgulanan bilgi maddeleri arasındaki korelasyonlar Pearson ki-kare testi kullanılarak incelenmiş ve tüm sorularla olan ilişkiler p değer aralığı olarak sunulmuştur. $\mathrm{p}<0,05$ istatistiksel anlamlı olarak değerlendirildi. ** İstatistiksel anlamlı 
Bilgi sorularına verilen cevaplar incelendiğinde ebeveynlerin yarısından çoğunun uyku apnesinin tanımını $(\% 57,7)$, horlamanın uyku apnesinin başlıca işaretlerinden birisi olduğunu (\%51,5), uyku apnesi varlığının belirlenebilmesi için özel bir tetkik gerektiğini $(\% 50,8)$ ve çocuklarda görülen uyku apnesinin kendiliğinden geçmeyip tedavi edilmesi gerektiğini $(\% 50,4)$ bildikleri izlendi. Etyoloji, semptomlar, teşhis, sonuçlar ve tedaviler hakkındaki diğer bilgi soruları ebeveynlerin çoğu tarafından bilmiyorum olarak cevaplandı (Tablo 1).

Demografik değişkenlerle bilgi düzeyi arasındaki ilişki incelendiğinde cinsiyet, yaş, gelir getiren işte çalışma durumu, 12 yaşına kadar ve halen yaşadığı yer, ekonomik durum, ailede sağlık personeli olup olmaması ve sağlıkla ilgili bir konuda eğitime katılıp katılmamış olması bilgi düzeyi ile iliş̧ili değilken ( $p>0,05)$, eğitim seviyesi ile pediatrik uyku apnesi hakkındaki bilgi sorularına verilen doğru cevaplar arasında istatistiksel olarak anlamlı ilişki mevcuttu $(p<0,05)$ (Tablo 2$)$.

\section{TARTIŞMA}

Obstrüktif uyku apnesi sendromu gibi kronik hastalıkların teşhis ve tedavisi önündeki en büyük engel hastaların teşhis için önerilen testlere, tedavi yöntemlerine veya hayat tarzı değişikliklerine gösterdikleri dirençtir. Diyabet, hipertansiyon ve kistik fibrozis hastalarında yapılan çalışmalar bireylerin hastalık hakkındaki bilgi eksikliğinin sağlıkla ilgili davranışlarda olumsuzluğa, yönlendirme yapılsa bile teşhisin konabilmesi için gerekli yerlere başvurmamalarına ve tedavide koopere olmamalarına yol açtığını göstermektedir. ${ }^{16-18}$ Owens $^{19}$ yaptığı çalışmada doktorların, çocuklarda bir uyku problemi varsa bunun ebeveynler tarafından belirlenip kendilerine belirtilmesini beklediklerini göstermiştir. Pediatrik uyku apnesinin çocukların gelişiminde ve sağlığında yaratabileceği olumsuzluklar düşünüldüğünde ebeveynlerin bilgi düzeylerinin belirlenmesi bu nedenle büyük önem taşımaktadır.

Çalışmamızda ebeveynlerin pediatrik uyku apnesiyle ilgili bilgi düzeylerinin yetersiz olduğu görülmüştür. Uyku apnesinin tanımını, horlamanın uyku apnesinin başlıca işaretlerinden birisi olduğunu, uyku apnesi varlığının belirlenebilmesi için özel bir tetkik gerektiğini ve çocuklarda görülen uyku apnesinin kendiliğinden geçmeyip tedavi edilmesi gerektiğini ebeveynlerin yarısından fazlası (sırasıyla \%57,7; \%51,5; \%50.8; \%50.4) biliyordu. Yani bireylerin yarısından çoğunun doğru cevap verdiği soruların oranı \%22'ydi. Ancak etyoloji, semptomlar, teşhis, sonuçlar ve tedaviler hakkındaki bilgi soruları \%41,5-\%80,4 oranında bilmiyorum olarak cevaplanmıştı. Bizim çalışmamıza benzer şekilde Schreck ve Richdale ${ }^{20}$, Amerikalı ebeveynlerin çocuklarının uyku problemleriyle ilgili bilgilerinin yetersiz olduğunu ve çocukluk döne- mindeki uyku problemlerinde uyku apnesi gibi spesifik alt başlıklarla ilgili bilgi sorularının sadece \%25'ine doğru cevap verebildiklerini göstermişlerdir. Strocker ve Shapiro $^{21}$ ise adenotonsiller hipertrofiye sekonder gelişen uyku apnesi ve tonsillektominin faydası ile ilgili Amerikan ebeveynlerin bilgi düzeyinin yetersiz olduğunu rapor etmişlerdir.

Diş hekimlerinin hastalarını tıbbi hastalıklar yönünden değerlendirmesi risk altındaki hastaların daha erken tespit edilmesine ve hastaların teşhis ve tedavi için gerekli bölümlere yönlendirilmesine yardımcı olabilir. ${ }^{22}$ Son yıllarda yapılan çalışmalar hem hastaların hem de diş hekimlerinin, muayene sırasında bireylerin bazı tıbbi hastalıklar yönünden değerlendirilmesine olumlu baktığını göstermektedir. ${ }^{23,24}$ Sağlık hizmetlerinde bu şekilde bir bütünleşik yaklaşım, obstrüktif uyku apnesi gibi hastalıkların uzun dönem olumsuz etkilerinin azaltılmasına yardımcı olabilir. Bizim çalışmamızda da ebeveynlerin büyük çoğunluğu diş hekimlerinin ve ortodontistlerin tıbbi hastalık riskleri yönünden çocuklarında değerlendirme yapmasının çok önemli olduğu görüşündeydi. Ebeveynlerin \%94'ü ortodontistin çocuklarını uyku apnesi riski yönünden değerlendirmesini isteyeceklerini ve \%99'u eğer ortodontist yönlendirirse uyku apnesi açısından değerlendirilmek üzere çocuklarını doktora götüreceklerini belirttiler. Bu bulgu, özellikle çocukluk döneminde ortodontik problemler ve çürük nedeniyle diş hekimlerinin sık gidilen bir hekim grubu olduğu düşünüldüğünde, pediatrik uyku apnesinin erken teşhisi açısından büyük bir imkan oluşturabilir.

Demografik değişkenlerle bilgi düzeyi arasındaki ilişki incelendiğinde sadece eğitim seviyesi pediatrik uyku apnesi hakkındaki bilgi sorularına verilen cevaplar ile istatistiksel olarak anlamlı düzeyde pozitif korelasyon gösterdi. Literatürde kronik hastalıklarla ilgili bilgi düzeyinin eğitim seviyesiyle ilişkisi konusunda çelişkili sonuçlar mevcuttur. Deis ve ark.'ları ${ }^{25}$ astımı olan çocuklarda ilaçların kullanım düzeyinin ebeveynin eğitim düzeyi lise seviyesinin üstüne çıktığında arttığını ve bu ebeveynlerin tedavi konusunda daha bilgili olduğunu rapor etmişlerdir. Schreck ve Richdale ${ }^{20}$ ise üniversite ve üstü düzeyde eğitimi olan bireylerle olmayan bireyler arasında çocuklarda uyku bozukluklarıyla ilgili bilgi düzeyinin anlamlı bir fark göstermediğini bulmuşlardır. Bu nedenle bilgi düzeyini etkileyebilecek faktörlerin ilerideki çalışmalarda daha detaylı değerlendirilmesi gereklidir.

Çalışmamızdaki bireyler uyku apnesi hastalığıyla ilgili bilgileri sırasıyla aile ve/veya arkadaş çevrelerinden (\%49), internet sitelerinden (\%42), televizyondan (\%34), doktordan (\%27) ya da gazete/dergilerden (\%15) edindiklerini söylediler. Sadece 3 hasta bu bilgiyi diş hekiminden aldıklarını belirttiler. Amerika'da yapılan bir araştırmada ise kişilerin sağlıkla ilgili bilgi edinmek için doktor veya ben- 
kişilerin sağlıkla ilgili bilgi edinmek için doktor veya benzeri sağlık çalışanlarına (\%86) ve aile/arkadaş çevresine (\%68) danıştıkları, \%57'sinin internete ve \%54'ünün kitap veya diğer basıı referans kaynaklarına baktıkları belirlenmiştir. ${ }^{26}$ Çalışmamızda bireylerin başlıca bilgi kaynağı olarak aile/arkadaş çevrelerini belirtmesi ilgi çekici bir bulgudur. Kişilerin neden bilgi almak için ilk olarak sağlık çalışanlarına danışmadığının sebepleri araştırmamızın kapsamının dışındadır ancak bireylerin sağlıklı bilgiye ulaşmasını sağlamak hastalarla hekimler arasındaki iletişimin arttırılmasıyla mümkün olabilir. Illave olarak, toplumda sağlıkla ilgili bilginin nereden edinildiği ve bunların sebepleri ileri çalışmalarda belirlenmelidir.

$\mathrm{Bu}$ araştırmanın bulguları ortodonti kliniklerine çocuklarının tedavisi için başvuran ebeveynlerin pediatrik uyku apnesi konusundaki bilgilerinin yetersiz olduğunu gösterse de genelleme yaparken çalışmamızın potansiyel sınırlamaları da göz önünde bulundurulmalıdır. Bu sınırlamalardan birincisi standardize olmayan bir anket kullanılmasıdır. Bunun sebebi literatürde obstrüktif uyku apnesi hakkında genel bilgi düzeyinin belirlenebileceği geçerliliği gösterilmiş bir anket olmamasıdır. Diğer bir sınırlama ise araştırmanın sosyoekonomik düzeyi orta ve üzeri sayılabilecek bireyler ile gerçekleştirilmiş olmasıdır. Daha düşük sosyoekonomik düzeydeki ebeveynlerde bilgi düzeyinin daha da düşük olması beklenebilir. Bu nedenle farklı örneklem gruplarında bilgi düzeyi belirlenmeli ve toplumda bu hastalığın farkındalığını arttırmak için eğitsel girişimlerde bulunulmalıdır.

\section{SONUÇLAR}

Sonuçlar ortodonti kliniğine başvuran ebeveynlerin çocuklarının uyku apnesi yönünden incelenmesine olumlu baktığını göstermiştir. Ancak bilgi düzeylerinin düşüklüğü, ebeveynler arasında pediatrik uyku apnesi farkındalığını arttırmak için eğitsel yöntemlerin geliştirilmesi ve ortodontistlerin ebeveynleri eğitmek için proaktif bir yaklaşım içinde olması gerekliliğini ortaya koymuştur.

\section{KAYNAKLAR}

1. American Academy of Pediatrics. Clinical Practice Guideline: Diagnosis and Management of Childhood Obstructive Sleep Apnea Syndrome. Pediatrics 2002; 109: 704-712.

2. Kaditis AG, ve ark. Obstructive sleep disordered breathing in 2- to 18-year-old children: diagnosis and management. Eur Respir J 2016; 47: 69-94.

3. Bonuck KA, ve ark. Prevalence and persistence of sleep disordered breathing symptoms in young children: a 6-year population-based cohort study. Sleep 2011; 34: 875-884.

4. Gozal D, Kheirandish-Gozal L. Obesity and excessive daytime sleepiness in prepubertal children with obstructive sleep apnea. Pediatrics 2009; 123: 13-18.

5. Taner T, Sağlam Aydınatay B. Physiologic and dentofacial effects of mouth breathing compared to nasal breathing. In: Önerci TM, editor. Nasal physiology and pathophysiology of nasal disorders. Berlin Heidelberg: Springer-Verlag; 2013. p. 567-88.

6. Cakirer B, ve ark. The relationship between craniofacial morphology and obstructive sleep apnea in whites and in African-Americans. Am J Respir Crit Care Med 2001; 163: 947-950.

7. Flores-Mir C, ve ark. Craniofacial morphological characteristics in children with obstructive sleep apnea syndrome: a systematic review and meta-analysis. J Am Dent Assoc 2013; 144: 269-277.

8. Capdevilla OS, Kheirandish-Gozal L, Dayyat E, Gozal D. Pediatric obstructive sleep apnea: complications, management, and long-term outcomes. Proc Am Thorac Soc 2008; 15: 274-282.

9. Dehlink E, Tan HL. Update on paediatric obstructive sleep apnoea. J Thorac Dis 2016; 8: 224-235.

10. Reiter $\mathrm{J}$, Rosen D. The diagnosis and management of common sleep disorders in adolescents. Curr Opin Pediatr 2014; 26: 407-412.

11. Cole AM. The role of dentistry in the field of sleep medicine...are we respecting the physiology? Cranio 2014; 32: 9-10.

12. Gauthier $L$, ve ark. Position paper by Canadian dental sleep medicine professionals on the role of different health care professionals in managing obstructive sleep apnea and snoring with oral appliances. Can Respir $J$ 2012; 19: 307-309.

13. Bian $\mathrm{H}$. Knowledge, opinions, and clinical experience of general practice dentists toward obstructive sleep apnea and oral appliances. Sleep Breath 2004; 8: 85-90.

14. Forrest CB, Shadmi E, Nutting PA, Starfield B. Specialty referral completion among primary care patients: results from the ASPN Referral Study. Ann Fam Med. 2007; 5: 361-367.

15. Carpenter CJ. A meta-analysis of the effectiveness of health belief model variables in predicting behavior. Health Commun. 2019; 25: 661-669.

16. Balfour $L$, ve ark. Development and psychometric validation of a cystic fibrosis knowledge scale. Respirology 2014; 19: 1209-1214.

17. Mahon AM, Moore GD, Gazes MI, Chusid E, MacGilchrist C. An Investigation of Diabetes Knowledge Levels Between Newly Diagnosed Type 2 Diabetes Patients in Galway, Ireland and New York, USA: A Cross-Sectional Study. Int J Low Extrem Wounds 2016; 15: 194-202.

18. Chatziefstratiou AA, Giakoumidakis K, Fotos NV, Baltopoulos G, Brokalaki-Pananoudaki H. Translation and validation of the Greek version of the hypertension 
knowledge-level scale. J Clin Nurs 2015; 24: 3417-24.

19. Owens JA. The practice of pediatric sleep medicine: results of a community survey. Pediatrics 2001; 108: e51.

20. Schreck KA, Richdale AL. Knowledge of childhood sleep: a possible variable in under or misdiagnosis of childhood sleep problems. J Sleep Res 2011; 20: 589-97. 21. Strocker AM, Shapiro NL. Parental understanding and attitudes of pediatric obstructive sleep apnea adenotonsillectomy. Int J Pediatr Otorhinolaryngol 2007; 71: 1709-1715.

22. Miller CS, Westgate PM. Implications of medical screenings of patients arriving for dental treatment. J Am Den Assoc 2014; 145: 1027-1035.

23. Greenberg BL, Kantor ML, Jiang SS, Glick M. Patients' attitudes toward screening for medical conditions in a dental setting. J Public Health Dent 2012; 72: 28-35.

24. Greenberg BL, Glick M, Frantsve-Hawley J, Kantor ML. Dentists' attitudes toward chairside screening for medical conditions. J Am Dent Assoc 2010; 141: 52-62.

25. Deis JN, Spiro DM, Jenkins CA, Buckles TL, Arnold $\mathrm{DH}$. Parental knowledge and use of preventive asthma care measures in two pediatric emergency departments. J Asthma 2010; 47: 551-556.

26. Pew Research Center. Washington, DC: Pew Internet \& American Life Project; 2009. http://www.pewinternet. org/2009/06/11/the-social-life-of-health-information/ 